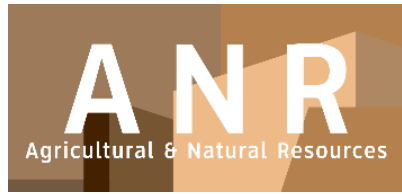

PAPER - OPEN ACCESS

\title{
Distribusi Kerapatan dan Kurva Stress-Strain pada Batang Kelapa Sawit
}

\author{
Author : Rudi Hartono \\ DOI $\quad: 10.32734 /$ anr.v1i1.131 \\ Electronic ISSN : 2654-7023 \\ Print ISSN : 2654-7015
}

Volume 1 Issue 2 - 2018 TALENTA Conference Series: Agricultural \& Natural Resources (ANR)

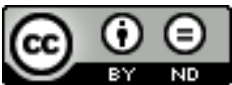

This work is licensed under a Creative Commons Attribution-NoDerivatives 4.0 International License.

Published under licence by TALENTA Publisher, Universitas Sumatera Utara
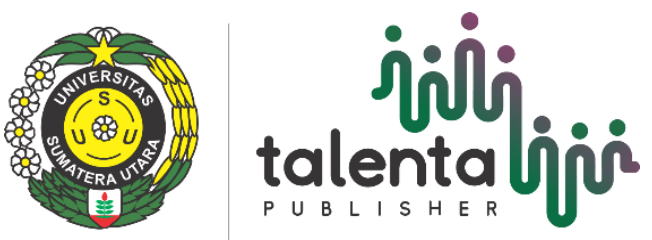


\title{
ن talentalioำ TALENTA Conference Series \\ Available online at https://talentaconfseries.usu.ac.id
}

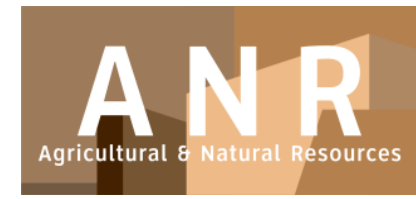

\section{Distribusi Kerapatan dan Kurva Stress-Strain pada Batang Kelapa Sawit}

\author{
Rudi Hartono ${ }^{\mathrm{a} *}$, Erwinsyah ${ }^{\mathrm{b}}$ \\ ${ }^{a}$ Fakultas Kehutanan, Universitas Sumatera Utara, Medan, 20155,Indonesia \\ ${ }^{b}$ Pusat Penelitian Kelapa Sawit, Medan, 20158,Indonesia \\ rudihartono_usu@yahoo.co.id
}

\begin{abstract}
The improvement quality of oil palm trunk could be done by compression. As based on to determining of compressing level, it was need to study the density distribution and stress-strain curve of oil palm wood. The three of oil palm trunk at 23 years old were cut. The specimen for density distribution was taken from $1 \mathrm{~m}, 3 \mathrm{~m}$ and $5 \mathrm{~m}$ of height of oil palm wood with dimension $2 \mathrm{~cm} \times 2 \mathrm{~cm} \times$ $2 \mathrm{~cm}$. The interval of it was $2 \mathrm{~cm}$ from the outer on the left to the right side. Then the specimen for stress-strain curve was taken from $1 \mathrm{~m}$ of height with interval of $2 \mathrm{~cm}$ from the outer to center of trunk. These specimens were taken at water saturated conditions. The result showed that density of oil palm wood was around $0.19-0.43 \mathrm{~g} / \mathrm{cm}^{3}$. The density distribution at outer side was high, then decreasing toward the center of trunk. The compressing level increased from the outer side to the center of oil palm trunk. In the outer side of oil palm trunk can be compressing until 58\% and the center side can be compressed until $71 \%$.
\end{abstract}

Keywords: oil palm trunk; compression; density distribution; stress-strain curve;

\section{Pendahuluan}

Indonesia memiliki perkebunan kelapa sawit yang cukup luas. Pada tahun 1995, luas areal perkebunan kelapa sawit di Indonesia hanya 1,91 juta ha tersebar di 6 propinsi, kemudian berkembang dengan cepat dan pada tahun 2015 luas areal perkebunan kelapa sawit telah mencapai 11,30 juta ha yang tersebar di 25 propinsi [7].

Mengingat potensinya yang sangat besar, pemanfaatan batang kelapa sawit (BKS) sebagai pengganti kayu merupakan salah satu alternatif yang sangat menjanjikan. Menurut Febrianto dan Bakar [3], peremajaan BKS dapat menghasilkan kayu gergaji sebanyak $50,1 \mathrm{~m}^{3} /$ ha dari $1 / 3$ bagian tepi batang yang keras, sedangkan $2 / 3$ bagian tengah batang yang lunak masih menjadi limbah. Namun pemanfaatan BKS memiliki beberapa permasalahan, antara lain variasi kerapatan yang tinggi $0,20-0,35 \mathrm{~g} / \mathrm{cm}^{3}$, kadar air berkisar $156-365 \%$, keawetan sangat rendah (kelas V) dan kelas kuat bervariasi dari III-V [1]. Ratanawilai et al. [10] mengemukakan bahwa sifat mekanik batang kelapa sawit dua kali lebih rendah dibandingkan kayu jati dan karet yang juga sering digunakan sebagai bahan furniture.

Modifikasi sifat-sifat kayu merupakan langkah yang perlu ditempuh sehingga kayu-kayu dengan kualitas rendah dapat meningkat baik dari sifat fisik maupun mekaniknya sehingga diharapkan ke depan dapat digunakan sebagai bahan baku industri perkayuan. Modifikasi kayu dapat dilakukan dengan cara modifikasi kimia, pemanasan, pemadatan ataupun kombinasi dari cara-cara tersebut. 
Salah satu usaha yang dilakukan untuk meningkatkan sifat fisis dan mekanis batang kelapa sawit adalah dengan cara memadatkannya (densifying by compression). Perlakuan pemadatan secara signifikan dapat meningkatkan sifat fisis dan mekansi seperti yang disampaikan oleh Kutnar and Kamke [8] dan Hartono et al. [5]. Kutnar and Kamke [8] mengemukakan bahwa pemadatan dengan tekanan 5,5 MPa pada kayu poplar hibrida (Populus deltoides $\times$ Populus trichocarpa) mampu meningkatkan kerapatan 98\%-208\%. Demikian juga Hartono et al. [5] mengemukakan bahwa pemadatan dapat meningkatkan kerapatan BKS dari $0.30 \mathrm{~g} / \mathrm{cm}^{3}$ menjadi $0.31-0.57 \mathrm{~g} / \mathrm{cm}^{3}$, atau meningkat sekitar $3,33 \% 90 \%$.

Namun sebelum dilakukan pemadatan, sangat perlu diketahui dahulu distribusi kerapatan batang kelapa sawit (BKS). Hal ini karena variasi kerapatan BKS yang sangat tinggi. Selain itu, perlu juga diketahui stress-strain dari BKS. Grafik stress-strain ini sangat penting untuk menentukan besarnya tingkat pemadatan yang akan dilakukan.

Berdasarkan hal tersebut di atas, maka tujuan penelian ini adalah untuk mengetahui distribusi BKS secara horizontal pada setiap ketinggian. Selain itu, perlu juga mengetahui kurva stress-strain untuk menentukan tingkat pemadatan yang akan dilakukan pada BKS.

\section{BAHAN DAN METODE}

\subsection{Bahan dan Alat}

Bahan utama yang digunakan dalam penelitian ini adalah BKS umur 23 tahun. Sedangkan alat yang digunakan adalah gergaji, oven, bak perendaman, caliper, desikator, timbangan digital, mesin UTM.

\subsection{Metode}

Sebanyak 3 pohon kelapa sawit umur 23 tahun yang berasal dari Kebun Percobaan Pusat Penelitian Kelapa Sawit (PPKS) Bukit Sentang di tebang. Contoh uji berupa disk setebal $10 \mathrm{~cm}$ diambil dari setiap pohon pada ketinggian 1 $\mathrm{m}, 3 \mathrm{~m}$ dan $5 \mathrm{~m}$. Selanjutnya contoh uji untuk distribusi kerapatan dibuat dengan ukuran $2 \times 2 \times 2 \mathrm{~cm}^{3}$ dengan interval jarak $2 \mathrm{~cm}$ dari tepi sebelah kiri ke tepi sebelah kanan pada setiap ketinggian batang (Gambar 1). Ulangan untuk pengujian kerapatan sebanyak 3 ulangan. Seluruh contoh uji kerapat di oven pada suhu $60{ }^{\circ} \mathrm{C}$ selama 3 hari. Selanjutnya ditimbang beratnya dan diukur volumenya.
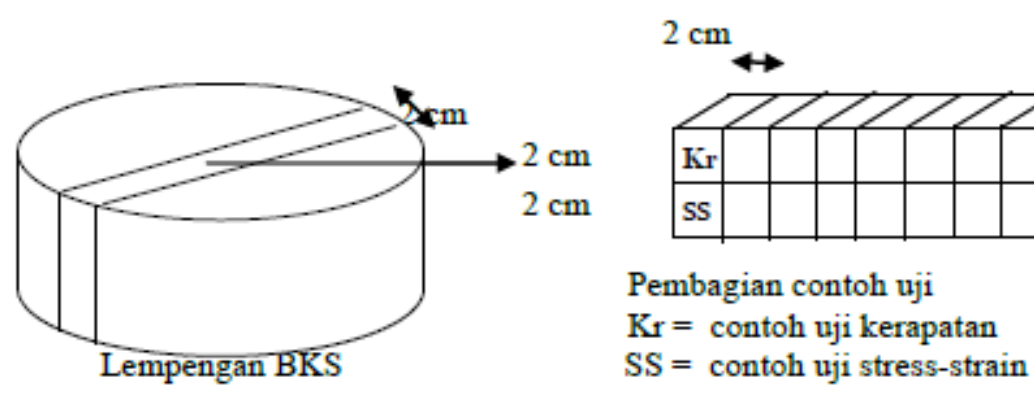

Gambar 1. Cara pengambilan dan pembuatan contoh uji kerapatan dan stress-strain

Contoh uji stress-strain dibuat dengan ukuran $2 \times 2 \times 2 \mathrm{~cm}^{3}$ dengan jarak $2 \mathrm{~cm}$ dari tepi sampai ke empulur. Pengambilan contoh uji hanya pada ketinggian $1 \mathrm{~m}$ pada kondisi kering udara. Kurva stress-strain dibutuhkan untuk menentukan besarnya tingkat pemadatan yang dapat dilakukan. Kurva stress-strain pada kayu umumnya mempunyai zonasi yaitu wilayah elastis (elastic region), selanjutnya wilayah plastis (collapse dominan region), dan kemudian meningkat dengan sangat tajam (post collapse region) yang menunjukkan bahwa dinding sel kayu telah mengalami tegangan maksimum atau mengalami kerusakan [11]. Untuk mengetahui tingkat pemadatan maksimal yang dapat 
dilakukan, dicari perpotongan garis antara wilayah plastis dan wilayah post collapse region seperti terlihat pada Gambar 2. Seluruh contoh uji stress-strain di ukur volumenya. Selanjutnya dilakukan pengujian stress-strain dengan menggunakan mesin UTM.

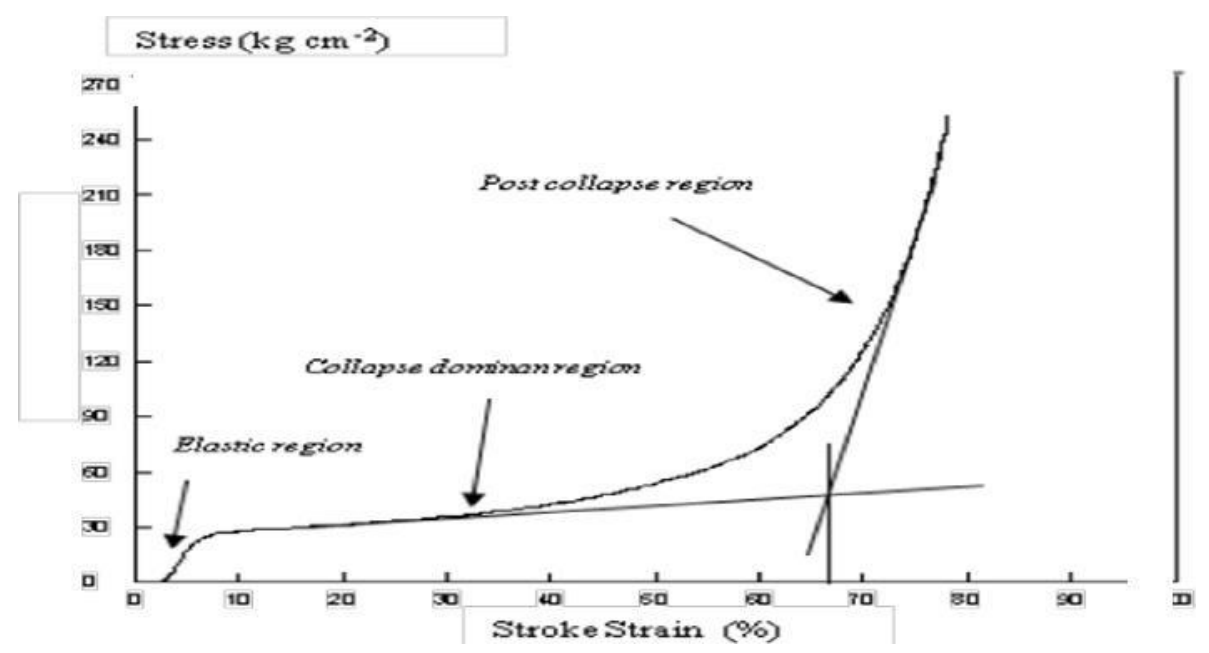

Gambar 2. Penentuan tingkat pemadatan maksimal

\section{Hasil Dan Pembahasan}

\subsection{Distribusi Kerapatan}

Kerapatan BKS berkisar antara $0,19-0,43 \mathrm{~g} / \mathrm{cm}^{3}$. Secara umum, distribusi kerapatan BKS secara lateral dapat dilihat pada Gambar 3.

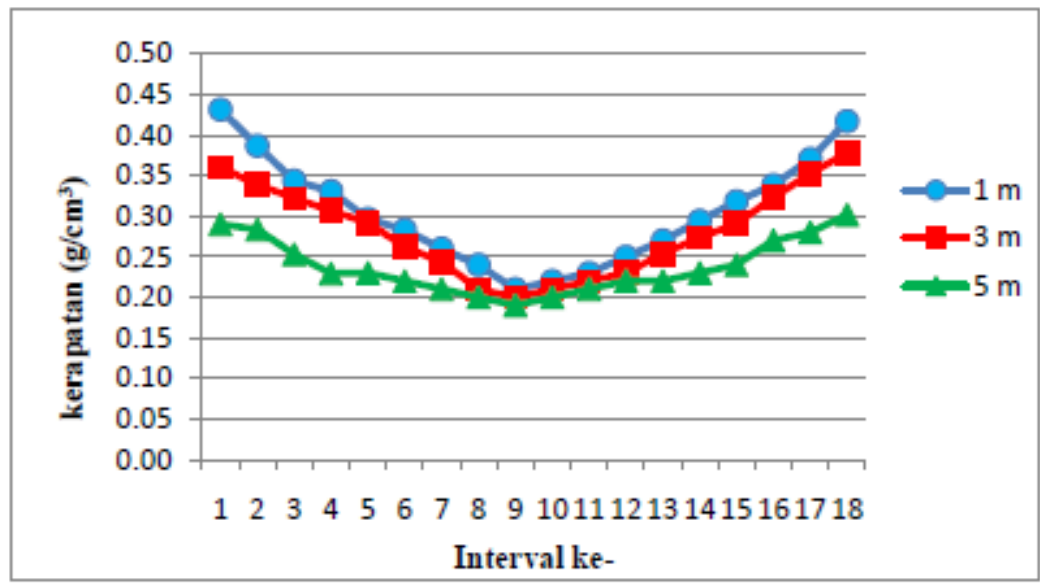

Gambar 3. Distribusi kerapatan batang kelapa sawit pada berbagai ketinggian batang

Pada Gambar 3, dapat dilihat bahwa pola distribusi kerapatan BKS pada ketinggian $1 \mathrm{~m}, 3 \mathrm{~m}$, maupun $5 \mathrm{~m}$ relatif sama. Secara vertikal pada bagian tepi luar, maka kerapatan BKS tertinggi terdapat pada ketinggian $1 \mathrm{~m}$ (bagian 
pangkal), diikuti ketinggian $3 \mathrm{~m}$ dan $5 \mathrm{~m}$. Sedangkan jika dilihat secara lateral, kerapatan tertinggi berapa pada bagian tepi, kemudian menurun pada bagian tengah dan terendah terdapat pada bagian empulur. Kerapatan BKS bervariasi berdasarkan umur. Semakin bertambah umur, maka kerapatan bagian tepi semakin tinggi. Pada umur 25 tahun kerapatan antara 0,18-0,43 $\mathrm{g} / \mathrm{cm}^{3}$ [2], sedangkan umur 40 kerapatan antara 0,23-0,74 $\mathrm{g} / \mathrm{cm}^{3}$ [4]. Nilai tertinggi dihasilkan pada bagian tepi, sedangkan nilai terendah pada bagian pusat atau tengah.

Erwinsyah [2] telah membuat pola zonasi kerapatan batang kelapa sawit seperti pada Gambar 4.

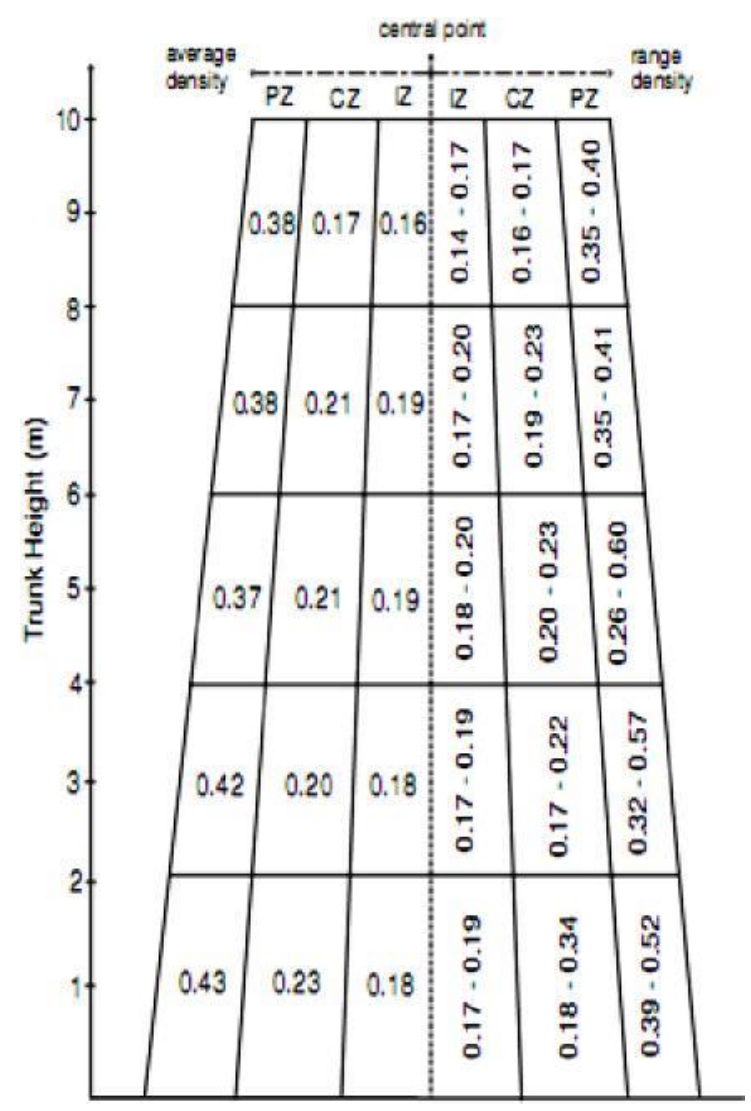

Gambar 4. Klasifikasi distribusi kerapatan batang kelapa sawit sepanjang batang. Nilai rataan dan selang kerapatan $\left(\mathrm{g} / \mathrm{cm}^{3}\right)$ untuk setiap zone disajikan dari sisi kiri dan sisi kanan dari tampak depan [2].

Tingginya kerapatan di bagian tepi dibandingkan di bagian tengah dan pusat disebabkan pada bagian tepi di dominansi oleh vascular bundle sehingga kerapatannya tinggi, sedangkan bagian tengah atau empulur di dominasi oleh parenkim dasar sehingga kerapatannya rendah (Gambar 5). Demikian juga kadar lignin vascular bundle yang terdapat di bagian tepi lebih tinggi dibagian tengah maupun pusat/empulur. Hal ini akan mempengaruhi berat jenis/kerapatan kayunya [9]. 


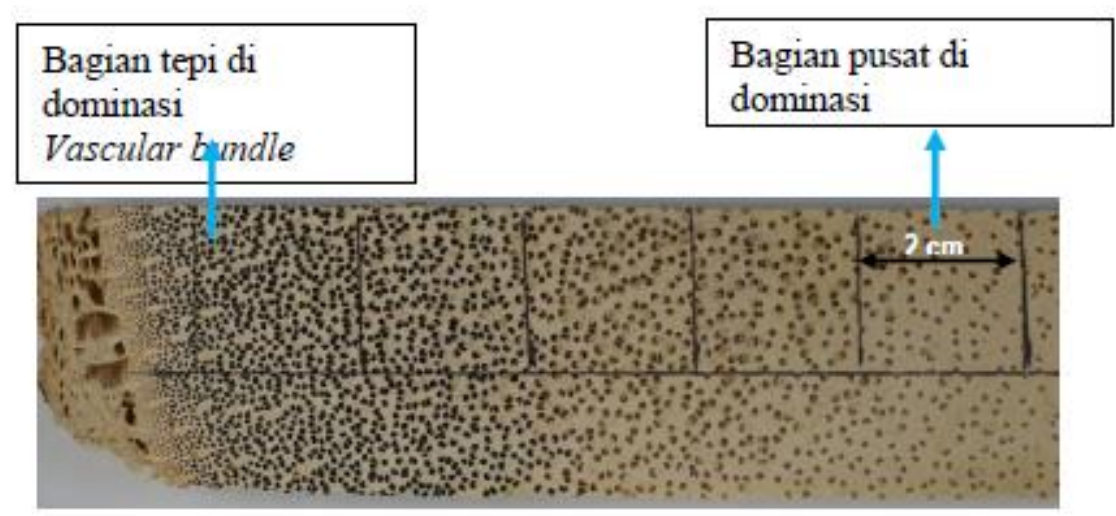

Gambar 5. Distribusi vascular bundle dari bagian tepi ke bagian tengah/pusat

Jika dibandingkan kayu kelapa, maka kerapatan batang kelapa lebih tinggi dibandingkan kerapatan kayu sawit. Wardhani (2005) mengemukakan bahwa kerapatan kayu kelapa berkisar antara $0,28-1,11 \mathrm{~g} / \mathrm{cm}^{3}$ dengan rerataan $0,61 \mathrm{~g} / \mathrm{cm}^{3}$. Hal ini karena jumlah dan kerapatan vascular bundle lebih rapat dibandingkan batang kelapa sawit.

\subsection{Kurva Stress-Strain}

Kurva stress-strain pada pemadatan dibutuhkan untuk menentukan besarnya tingkat pemadatan yang bias dilakukan. Kurva stress-strain mempunyai pola yaitu pada awalnya merupakan garis linier, diikuti dengan garis datar yang memanjang dan kemudian meningkat dengan sangat tajam [6]. Pada pola kurva stress-strain, garis linier menunjukkan wilayah elastis, garis datar yang memanjang menunjukkan wilayah plastis, dan garis yang meningkat tajam menunjukkan kayu telah mengalami tegangan maksimum atau mengalami kerusakan.

Jika kayu diberi beban, maka kayu akan mengalami perubahan bentuk (terjadi deformasi). Pada wilayah elastis, apabila kayu diberi beban dan kemudian beban dilepaskan, maka kayu akan kembali ke bentuk semula. Pada wilayah plastis, apabila kayu diberi beban, dan kemudian beban dilepaskan, maka kayu akan mengalami perubahan bentuk yang tetap, meskipun belum terlihat rusak. Pada wilayah plastis ini kegiatan pemadatan dilakukan sesuai dengan tingkat pemadatan yang diinginkan.

Kurva stress-strain batang kelapa sawit dalam penelitian ini menggunakan kondisi kering udara. Contoh uji untuk kurva stress-strain ini diambil dari arah tepi hingga ke pusat batang dengan interval jarak $2 \mathrm{~cm}$. Kurva stress-strain batang kelapa sawit pada kondisi kering dapat dilihat pada Gambar 6. 


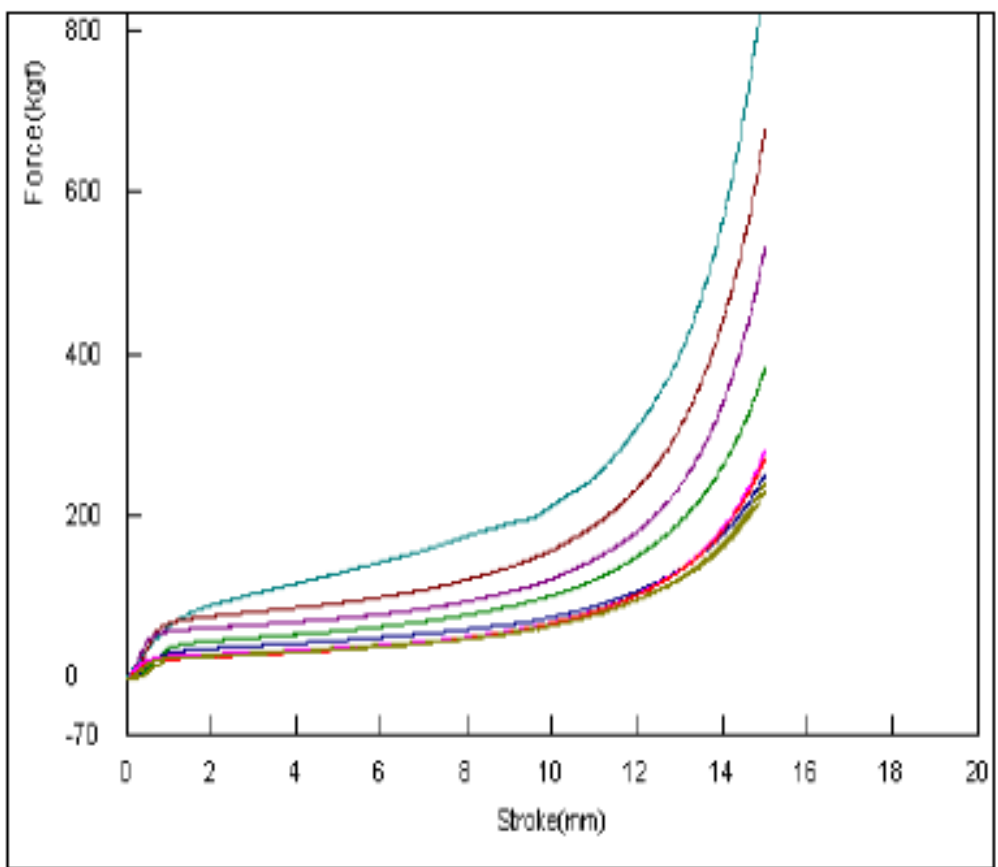

Gambar 6. Kurva stress-strain BKS pada kondisi kering udara

Keterangan : Angka 1 menggambarkan interval ke-1, angka 2 menggambarkan interval ke-2, angka 3 menggambarkan interval ke-3 dst.

Berdasarkan kurva stress-strain pada Gambar 6, maka dapat ditentukan pemadatan maksimal. Pemadatan maksimal ditentukan berdasarkan perpotongan antara garis datar plastis dengan garis yang meningkat tajam. Pemadatan maksimal BKS pada kondisi kering udara dapat dilihat pada Tabel 1.

Tabel 1. Tingkat pemadatan maksimal BKS pada kondisi kering udara

\begin{tabular}{ccc}
\hline Interval ke- & Kerapatan rata-rata $\left(\mathrm{g} / \mathrm{cm}^{3}\right)$ & Tingkat Pemadatan $(\%)$ \\
\hline 1 & 0,43 & 58 \\
2 & 0,39 & 60 \\
3 & 0,34 & 62 \\
4 & 0,33 & 65 \\
5 & 0,30 & 68 \\
6 & 0,28 & 68 \\
7 & 0,26 & 68 \\
8 & 0,23 & 70 \\
9 & 0,21 & 71 \\
\hline
\end{tabular}

Berdasarkan Tabel 1 tersebut dan berdasarkan grafik stress-strain tersebut dapat diketahui bahwa batang kelapa sawit usia 23 tahun dalam kondisi kering udara dengan kerapatan 0,21-0,43 $\mathrm{g} / \mathrm{cm}^{3}$ dapat dipadatkan dengan tingkat pemadatan $58-71 \%$. 
Jika dihubungkan dengan Gambar 3 kerapatan BKS bagian luar 0,43 g/ $\mathrm{cm}^{3}$. Kerapatan BKS bagian luar yang lebih keras karena di dominasi oleh vascular bundle dibandingkan parenkim dasar, sehingga membutuhkan energy lebih besar untuk memadatkan kayu dan pemadatan maksimal yang dapat dilakukan pada BKS bagian luar mencapai $58 \%$.

BKS bagian tengah/pusat di dominasi oleh parenkim dasar dibandingkan vascular bundle, sehingga untuk memadatkan bagian tengah membutuhkan energy yang kecil. Semaki kecil kerapatan, maka energy yang dikeluarkan untuk memadatkan juga semakin kecil. Pemadatan maksimal untuk kerapatan yang paling rendah $\left(0,21 \mathrm{~g} / \mathrm{cm}^{3}\right)$ adalah $71 \%$.

\section{Kesimpulan}

Distribusi kerapatan pada BKS secara horizontal, pada bagian tepi (dekat kulit) lebih tinggi kemudian menurun menuju ke arah pusat batang, selanjutnya naik kembali menuju ke arah kulit. Secara vertikal, kerapatan BKS pada bagian pangkal tinggi, kemudian menurun seiring meningkatnya ketinggian. Batang kelapa sawit bagian pangkat dapat dipadatkan dengan tingkat kepadatan 58-71\%.

\section{Referensi}

[1] Bakar, E. S. 2003. Kayu Sawit sebagai Substitusi Kayu dari Hutan Alam. Forum Komunikasi Teknologi dan Industri Kayu. Jurusan Teknologi hasil Hutan Fakultas Kehutanan IPB Volume 2/1/Juli 2003. Bogor.

[2] Erwinsyah. 2008. Improvement of Oil Palm Wood Properties Using Bioresin. Institut für Forstnutzung und Forsttechnik. Fakultät für Forst-, Geo- und Hydrowissenschaften. Technische Universität Dresden. Dissertation.

[3] Febrianto, F., E.S. Bakar. 2004. Kajian Potensi, Sifat-sifat Dasar dan Kemungkinan Pemanfaatan Kayu Karet dan Biomassa Sawit di Kabupaten Musi Banyuasin. Kerjasama antar Pemerintah Daerah Musi Banyuasin dengan Lembaga Manajemen Agribisnis Agroindustri IPB.

[4] Hartono, R., I. Wahyudi, F. Febrianto, W. Dwianto. 2011. Pengukuran Tingkat Pemadatan Maksimum Batang Kelapa Sawit. Jurnal Ilmu dan Teknologi Kayu Tropis. Vol 9 (1), p 73-83.

[5] Hartono, R., I. Wahyudi, F. Febrianto, W. Dwianto, W. Hidayat, J.H. Jang, S.H. Lee, S.H. Park, N. H. Kim. 2016. Quality Improvement of Oil Palm Trunk Properties by Close System Compression Method. Journal of Korean Wood Science Technology. Vol 44(2): 172 183

[6] Hsu, W.E., Schwald, W., Schwald, J., Shields, J.A. 1988. Wood Science Technology. Vol. 22, p : 281289

[7] Kementerian Pertanian. 2016. Pusat Data dan Informasi Pertanian. Https://aplikasi.pertanian.go.id/bdsp/hasil lok.asp. (diakses 16 april 2016).

[8] Kutnar, A., Kamke, F.A. 2012. Compression of wood under saturated steam, superheated steam, and transient conditions at $150{ }^{\circ} \mathrm{C}, 160{ }^{\circ} \mathrm{C}$, and 170 ${ }^{\circ} \mathrm{C}$. Wood Science and Technology 46(1): $73 \sim 88$.

[9] Rahayu, I.S. 2001. Sifat Dasar Vascular Bundle dan Parenchyme Batang batang kelapa sawit (Elaeis guineensis Jacq) Dalam Kaitannya dengan Sifat Fisis, Mekanis, serta Keawetannya. Program Studi Ilmu Pengetahuan Kehutanan. Facultas Pasca Sarjana IPB. Thesis. Tidak Diterbitkan

[10] Ratanawilai, T., T. Chumthong, S. Kirdkong. 2006. An Investigation on The Mechanical Properties of Trunks of Palm Oil Tree for The Furniture Industry. Journal of Oil Palm Research 114-121.

[11] Shams, M.I., N. Kagemori, H. Yano. 2004. Compressive Deformation of Wood Impregnated with Low Molecular Weight Phenol Formaldehyde (PF) Resin I: Effects of Pressing Pressure and Pressure Holding. J Wood Sci 50 : 337-342.

[12] Wardhani, I.Y. 2005. Kajian Sifat Dasar dan Pemadatan Bagian Dalam Kayu Kelapa (Cocos nucifera L). Sekolah Pasca Sarjana IPB. Disertasi. Tidak Diterbitkan. 